\title{
Effects of Soil and Water Conservation Practices in Selected Soil Physicochemical Properties: The Case of Ezha District, Southern Ethiopia
}

\author{
Abdrahman Shafi ${ }^{1^{*}} \quad$ Achalu Chimdi $^{2} \quad$ Teshome Yitbarek ${ }^{3}$ \\ 1. Department of Natural Resource Management, Debark University College of Agriculture and Environmental \\ Science (DKU CAES), P.O Box 90, Debark, North Gondar, Ethiopia \\ 2. Department of Soil Science, Ambo University College of Agriculture and Natural Resources Management, \\ Ambo, Ethiopia \\ 3. Department of Natural Resource Management, Wolkite University College of Agriculture and Natural \\ Resources Management, Wolkite, Ethiopia
}

\begin{abstract}
Soil erosion is one of the major factors that lead to poor soil productivity in Sub-Saharan Africa. Ever increasing population has driven the populace to inhabit marginal frontiers worsening the soil erosion and food insecurity. Farmers in the study area cultivate formerly untouched communal lands and forest lands by clearing natural vegetations. This exposes to soil fertility loss due to soil erosion resulting in a decline in crop yield. Therefore, this study was aimed at evaluating the effects of soil and water conservation measures on selected soil physicochemical properties in the study area. To determine the effect of soil and water conservation on the selected soil properties, soil analysis was undertaken by taking composite soil samples from conserved and unconserved lands of adjacent sites after categorizing their slopes in to three levels (low, medium and high). Composite soil samples from natural forest were taken and analyzed, and used as control. Most of the selected soil physicochemical properties were affected by soil and water conservation measures. Highest bulk density $\left(1.56 \mathrm{~g} / \mathrm{cm}^{3}\right)$ was recorded in the unconserved land. The highest mean value of soil moisture content $(22.2 \%)$ was recorded in the forest soil. Comparing the two farm lands, higher mean values of soil $\mathrm{pH}$, organic matter, organic carbon, total nitrogen, available phosphorus, cation exchange capacity, exchangeable calcium and magnesium were also recorded in the conserved land. Considering the recorded values, the study recommends that implementation of soil and water conservation should be widely practiced in the district. In order to enhance the community adoption towards soil and water conservation, further effort is required.
\end{abstract}

Keywords: Adoption, soil erosion, soil productivity, soil properties, soil and water conservation

DOI: $10.7176 / \mathrm{JBAH} / 9-7-02$

Publication date: April $30^{\text {th }} 2019$

\section{INTRODUCTION}

Land degradation is causing a decline in crop productivity and huge economic loss, putting the food security and livelihood of farmers at risk. Soil erosion is the main form of land degradation caused by the interacting effects of factors, such as biophysical characteristics and socio-economic aspects. Each year about 10 million hectares of cropland of the globe is being lost due to soil erosion (Pimentel \& Burgess, 2013). In sub-Saharan Africa (SSA), land degradation particularly, nutrient depletion is leading to a decline in crop productivity, and has been linked to hunger and poverty (Coxhead \& Ygard, 2008).

Ethiopia is one of the most environmentally troubled countries in the Sahara belt. The principal environmental problem of the country is land degradation in the form of soil erosion and soil fertility loses (Singh \& Tripathi, 2013). According to the Environmental Protection Authority (EPA, 2003), about $45 \%$ of the total annual soil loss in the country occurs from cultivated fields. Due to widespread nutrient depletion in agricultural lands, productivity is decreasing (Bello et al., 2010). In fact, agriculture in Ethiopia is not only an economic activity but also a way of life for which agricultural land is an indispensable resource upon which the welfare of the society is built.

In order to narrow the production gap and to place the economy on higher growth trajectory, the Ethiopian government has planned to double agricultural production through scaling up the productivity of smallholder farmers. In line with this, Ministry of Agriculture developed soil fertility research to narrow knowledge gap about the country's soil fertility conditions. Based on this, Ministry of Agriculture (MoA) and several other stakeholders has launched the Ethiopian Soil Information System (Ethio SIS) project aimed at investigating the soil fertility status of the agricultural lands of the country and gene rating information that will guide fertilizer use (Wasim et al., 2010).

To grapple with problem of soil erosion massive restoration and soil and water conservation schemes were also launched in Ethiopia (Bello et al., 2010). Since 1969 various conservation strategies have been introduced to enhance agricultural development and rural livelihood. Many generous international donors assisted the program. 
Although the achievements were remarkable in quantitative terms, the impacts of these efforts were far below expectation and soil erosion continued to be a serious problem. There are several possible reasons for the failure of conservation interventions. These include farmers' misperception in planning and management. The extensive and uniform application of similar soil and water conservation measures also disregarded the local agro ecological and socio-economic variations (Woldeamlak, 2001). Even though, there is an attempt to implement soil and water conservation as other parts of the country, there are sever erosion impacts in the study area. The objective of this study was to assess community participation in soil and water conservation practices and to evaluate the effects of conservation measures on selected soil physicochemical properties in Ezha district, Southern Ethiopia.

\section{MATERIAL AND METHODS}

\section{General Description of the Study Area}

The study was conducted in Ezha district, southern Ethiopia. The district constitutes 29 local governmental units (kebeles). Its geographical location extends from $8^{\circ} 0^{\prime} 0^{\prime \prime} \mathrm{N}$ to $8^{\circ} 10^{\prime} 30^{\prime \prime} \mathrm{N}$ and $37^{\circ} 52^{\prime} 30^{\prime \prime}$ to $38^{\circ} 13^{\prime} 30^{\prime \prime} \mathrm{E}$ at an elevation ranging from 1200 to 2200 meters above msl. It has a total area of about 47820 . The capital of the district, Agenna, is located at a distance of $42 \mathrm{~km}$ from Wolkite and $192 \mathrm{~km}$ from Addis Ababa. Based on the 2007 census conducted by the central statistics agency (CSA), the district has a total population of 84,905 . The mean annual rainfall is about $1268.04 \mathrm{~mm}$. The average maximum and minimum temperature for the last ten years is $25^{\circ} \mathrm{C}$ and $11{ }^{\circ} \mathrm{C}$ respectively.

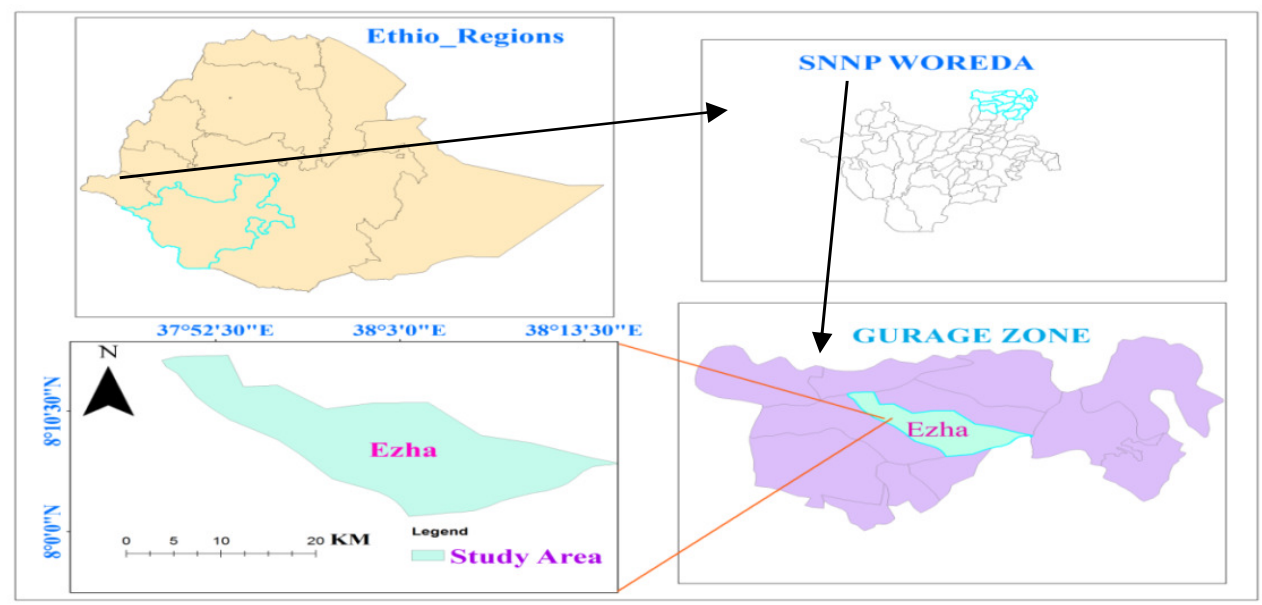

Soil sampling and laboratory analysis

Figure 1: Location map of the study area

Before the start of the experimental research, field survey was conducted. After selecting two adjacent farm lands, one in which old aged SWC measures are existed and the other farm land with no conservation measures, three slope positions (higher, medium and lower slope) were identified as done by Haweni (2015) in Dimma watershed, central Ethiopia. Soil samples at $0-20 \mathrm{~cm}$ depth were randomly taken from each slope positions of the conserved, unconserved and natural forest land by using soil auger. To prepare composite soil samples, the subsamples were mixed thoroughly in their respective land (conserved, unconserved and forest land) and slope level. A total of 27 composite soil samples (3treatments x 3slope positions x 3replications) were prepared after mixing and air drying the sub-samples as described by Motsara and Roy (2008). Then, the samples were properly handled in sampling bags and labeled. Two core ring soil samples from each land at each slope were also taken to evaluate the bulk density of the soil. Finally, samples were taken to Institute of Agricultural Research Center, Wolkite for analysis.

Soil texture was determined by hydrometer method (Gee \& Bauder, 1986). Soil moisture content was determined by gravimetric method. Bulk density was also determined by core method after drying a defined volume of soil in an oven dry at $105^{\circ} \mathrm{c}$ for 24 hours. Then, it was calculated by dividing the mass of the oven dried soil to the volume of the sampling core (Baruah \& Barthakur, 1997). Soil pH was measured potentiometrically in 1:2.5 soils: water ratio as described by Moberg (2000). Organic carbon was determined according to Walkley \& Black method (Schnitzer, 1982) and it was converted to OM by multiplying the percentage of carbon by 1.72; total nitrogen was analyzed by the Kjeldahl method (Bremner \& Mulvaney, 1982); Cation exchange capacity (CEC) and electrical conductivity of soil (EC) were measured according to (Rhoades et al., 1982). Total exchangeable bases were determined after leaching the soil by using ammonium acetate (Cottenie, 1980). Available Phosphorus (P) was determined using the standard Olsen extraction method (Olsen et al., 1954). 
The soil data recorded were subjected to analysis of variance using SAS software version 9.2 (SAS Institute, 2008) to test differences in selected soil physical and chemical properties among the conserved and unconserved lands, and the forest land.

\section{RESULTS AND DISCUSSION \\ Effects of Soil and Water Conservation on Selected Soil Physical Properties Soil texture}

Considering the particle size distribution, significant difference $(\mathrm{p}<0.01)$ was observed between the soil samples taken from the higher slope of the conserved and unconserved farm lands and the natural forest as well. There was also significant difference $(\mathrm{p}<0.01)$ in sand content at the lower slope of the three lands. In the middle slope, the variation of sand between the natural forest and the two farm lands was significant $(p<0.05)$. But, the difference in mean value of sand in between the conserved and unconserved lands at this slope was not significant. Relatively, higher mean value of sand $(58.89 \%)$ was recorded at the lower slope of the forest land. Comparing the two farm lands, high mean value of sand was recorded in the unconserved land. Mean percentage of sand in the upper, middle and lower slopes of the conserved land were found to be $52.44 \%, 50.33 \%$ and $25.67 \%$ respectively. Mean percentage of sand in the upper, middle and lower slope of the unconserved area were $47 \%, 47.66 \%$ and $46.6 \%$ respectively (Table 5). This finding is in agreement with the finding reported by Joas (2015). According to his finding, there was statistical significance difference in the clay, silt and sand due to different SWC techniques used in his study area.

The silt content in the cultivated lands was significantly $(\mathrm{P}<0.05)$ affected by SWC measures. But, the difference in silt content of the soil in the middle and lower slopes of the conserved farm land and the natural forest was not statistically significant. Numerically, highest mean value of silt $(18.33 \%)$ was recorded in the natural forest. It contradicts with the study conducted by Teshome et al. (2013) in impacts of land use on selected physicochemical properties of soils in Abobo area, western Ethiopia. Their finding revealed that silt content was significantly $(\mathrm{P}<0.01)$ higher in cultivated land than forest.

Table 5: Status of selected soil physical properties

\begin{tabular}{|c|c|c|c|c|c|c|c|}
\hline Slope & Treatment & & Sand $(\%)$ & Silt (\%) & Clay $(\%)$ & $\mathrm{BD}(\mathrm{g} / \mathrm{cm} 3)$ & $\mathrm{MC}(\%)$ \\
\hline \multirow{4}{*}{ Higher } & $\mathrm{CL}$ & Mean & $52.44^{\mathrm{a}}$ & $17^{\mathrm{a}}$ & $30.6^{\mathrm{a}}$ & $1.37^{\mathrm{a}}$ & $11.96^{\mathrm{a}}$ \\
\hline & UnL & Mean & $47^{b}$ & $14.33^{\mathrm{b}}$ & $40^{\mathrm{b}}$ & $1.56^{\mathrm{b}}$ & $11.17^{\mathrm{b}}$ \\
\hline & $\mathrm{FL}$ & Mean & $58^{c}$ & $18.33^{\mathrm{a}}$ & $24.00^{\mathrm{c}}$ & $1.32^{\mathrm{c}}$ & $16.99^{c}$ \\
\hline & & P-value & 0.0035 & 0.037 & 0.0003 & $<.0001$ & $<.0001$ \\
\hline \multirow{4}{*}{ Medium } & $\mathrm{CL}$ & Mean & $50.33^{\mathrm{a}}$ & $14.00^{\mathrm{a}}$ & $33.00^{\mathrm{a}}$ & $1.35^{\mathrm{a}}$ & $14.21^{\mathrm{a}}$ \\
\hline & UnL & Mean & $47.66^{\mathrm{a}}$ & $13.66^{\mathrm{b}}$ & $38.67^{\mathrm{b}}$ & $1.48^{\mathrm{b}}$ & $11.8^{\mathrm{b}}$ \\
\hline & $\mathrm{FL}$ & Mean & $57.89^{b}$ & $18.33^{\mathrm{a}}$ & $24.2^{\mathrm{c}}$ & $1.27^{\mathrm{c}}$ & $22.19^{c}$ \\
\hline & & P-value & 0.0345 & 0.082 & $<.0001$ & $<.0001$ & $<.0001$ \\
\hline \multirow{4}{*}{ Lower } & $\mathrm{CL}$ & Mean & $25.67^{\mathrm{a}}$ & $16.66^{\mathrm{a}}$ & $58.00^{\mathrm{a}}$ & $1.32^{\mathrm{a}}$ & $17.28^{\mathrm{a}}$ \\
\hline & UnL & Mean & $46.66^{\mathrm{b}}$ & $15.00^{\mathrm{b}}$ & $40.03^{b}$ & $1.47^{\mathrm{b}}$ & $12.93^{b}$ \\
\hline & FL & Mean & $58.89^{c}$ & $17.87^{\mathrm{a}}$ & $26.2^{\mathrm{c}}$ & $1.13^{\mathrm{c}}$ & $22.2^{\mathrm{c}}$ \\
\hline & & P-value & $<.0001$ & 0.0663 & $<.0001$ & $<.0001$ & $<.0001$ \\
\hline
\end{tabular}

Where, $\mathrm{CL}=$ conserved land, $\mathrm{UnL}=$ unconserved land, $\mathrm{FL}=$ forest land. $\mathrm{BD}=$ bulk density, $\mathrm{MC}=$ moisture content. Means within column followed by the same letter are not statistically significant from each other at $\mathrm{P}>0.05$.

Clay content of the soil at all slopes of the farm lands was significantly $(\mathrm{P}<0.01)$ affected by SWC practice (Table 5). The highest mean value of clay content (58\%) was observed at the lower slope where SWC measures are practiced. Mean percentage of clay in upper and middle slopes of the conserved land were $30.6 \%$ and $33 \%$ respectively. The average clay content in the upper, middle and lower slopes of the unconserved land were $40 \%, 38.67 \%$ and $40.03 \%$ respectively. With regard to slope level, higher clay content was observed in lower slope areas of both conserved and unconserved sites. Textural class of the soil in higher and middle slopes of the conserved land, at the middle slope of the unconserved land and in all the three slopes of the forest land was found to be sandy clay loam. Compared to the cultivated lands, clay content of the soil in the natural forest was lower. This finding contradicts with the report of (Mojiri et al., 2012). According to their finding, lower clay content was recorded in cultivated land than the soils in adjacent natural forest.

Soil bulk density

Soil bulk density is the most popular measure to assess the degree of soil compaction. It is related to the pore spaces in the soil indicating water holding capacity and aeration. In this study, soil bulk density was found to be significantly $(\mathrm{p}<0.01)$ affected by SWC practices. The highest mean value of soil bulk density $\left(1.56 \mathrm{~g} / \mathrm{cm}^{3}\right) \mathrm{was}$ recorded in the higher slope of the unconserved farm land. While, in the middle and lower slopes of the unconserved land, the average BD recorded were $1.48 \mathrm{~g} / \mathrm{cm}^{3}$ and $1.47 \mathrm{~g} / \mathrm{cm}^{3}$ respectively. The average value of soil bulk density recoded in the higher slope of the conserved land was $1.37 \mathrm{~g} / \mathrm{cm}^{3}$ (Table 5). Average BD of $1.32 \mathrm{~g} / \mathrm{cm}^{3}$ was recorded in the lower slope of the conserved land. 
In the case of the natural forest, mean value of bulk density recorded in the upper, middle and lower slopes were $1.32 \mathrm{~g} / \mathrm{cm}^{3}, 1.27 \mathrm{~g} / \mathrm{cm}^{3}$ and $1.13 \mathrm{~g} / \mathrm{cm}^{3}$ respectively. Generally, low soil bulk density was considered as the slope level gets lower. In line with this difference in soil bulk density due to conservation intervention, this study highly agreed with the study undertaken by Abay et al. (2016) on effects of graded stone bunds on selected soil properties in the central highlands of Ethiopia. According to his finding, higher soil bulk density was recorded in the agricultural land in which stone bunds were not constructed. Study conducted Haweni (2015) in Dimma watershed of central Ethiopia also indicated that soil under unconserved lands exhibits higher soil bulk density than soil under conservation lands.

\section{Soil moisture content}

Soil moisture content in all slope levels was significantly $(\mathrm{p}<0.01)$ affected by soil and water conservation practice. Comparing the two agricultural lands, the higher mean value of moisture (17.28\%) was recorded in soils of the conserved land and the lower mean value $(11.17 \%)$ was recorded under the unconserved land (Table 5). The mean value of soil moisture recorded in upper and middle slopes of the conserved land were $11.96 \%$ and $14.21 \%$ respectively. In middle and lower slopes of the unconserved land, the mean values of soil moisture were $11.8 \%$ and $12.93 \%$ respectively. However, soil moisture recorded in the forest land was relatively highest. The possible reasons for the recording of relatively high moisture in the conserved land might be due to higher water infiltration during rainy seasons as a result of soil and water conservation measures. This finding agreed with a study reported by Joas (2015) in Nyamasheke district, Rwanda. His finding indicated that treatments affect soil moisture. In his study, the highest soil moisture content was recorded in areas under SWC measures. Stroosnijder \& Hoogmoed (2004) also reported that soil and water conservation structures reduce runoff and evaporation and increases infiltration and soil moisture content.

\section{Effects of Soil and Water Conservation on Selected Soil Chemical Properties \\ Soil pH}

Soil $\mathrm{pH}$ is influenced by different anthropogenic and natural activities including leaching of exchangeable bases, acid rains, decomposition of organic materials, application of industrial fertilizers and farming practices (Papiernik et al., 2007). The analysis of variance revealed that at the upper slope, there was no significant difference $(\mathrm{p}>0.01)$ in soil $\mathrm{pH}$ between the conserved and unconserved cultivated lands. But, at the same slope the difference was significant $(\mathrm{p}<0.01)$ between soils of the forest and the farm lands. At the middle and lower slopes, significance difference $(\mathrm{p}<0.01)$ in soil $\mathrm{pH}$ was observed between the conserved and unconserved lands. The mean value of soil $\mathrm{pH}$ was highest (6.30) at upper and lower slope of the forest land and lowest (5.18) at the upper slope of the unconserved farm land. The recorded mean value of soil $\mathrm{pH}$ at the lower slope of the unconserved land was 5.33 (Table 6). The lower mean value of soil $\mathrm{pH}$ was observed in unconserved farm land. It could be attributed to the relatively lower base saturation and lower soil organic matter content due to lack of fallowing. Significant reduction in soil $\mathrm{pH}$ occurs in soil that is cultivated for several years (Habtamu et al., 2009).

\section{Electrical conductivity}

As the statistical result indicated, electrical conductivity of the soil did not significantly ( $\mathrm{p}>0.05$ ) affected by conservation. Relatively, high mean value of electrical conductivity $(0.42 \mathrm{~ms} / \mathrm{cm})$ was recorded in the unconserved farm land. However, the mean value of electrical conductivity (EC) at higher and middle slopes of the conserved land was $0.03 \mathrm{~ms} / \mathrm{cm}$ (Table 6). In the lower slope of the conserved land, EC was found to be $0.4 \mathrm{~ms} / \mathrm{cm}$. In the higher and middle slopes of the unconserved land, $0.2 \mathrm{~ms} / \mathrm{cm}$ and $0.19 \mathrm{~ms} / \mathrm{cm}$ mean values of EC were recorded respectively. This finding agreed with the study conducted by Lemma et al. (2015) in Hawassa Zuria district. As they reported EC under closed area with SWC was significantly lower than the EC of the soil under open grazing land. 
Table 6: Soil pH, OM, OC, TN, CEC and EC in cultivated lands and the forest land

\begin{tabular}{|c|c|c|c|c|c|c|c|c|}
\hline Slope & Treatment & & $\mathrm{pH}$ & $\mathrm{OM}$ & $\mathrm{OC}$ & $\mathrm{TN}$ & CEC & $\mathrm{EC}$ \\
\hline \multirow{4}{*}{$\begin{array}{l}\dot{\bar{\Phi}} \\
\frac{600}{00} \\
\dot{\Xi}\end{array}$} & $\mathrm{CL}$ & Mean & $5.33^{\mathrm{a}}$ & $5.84^{\mathrm{a}}$ & $3.406^{\mathrm{a}}$ & $0.27^{\mathrm{a}}$ & $27.95^{\mathrm{a}}$ & $0.03^{\mathrm{a}}$ \\
\hline & UnL & Mean & $5.18^{a}$ & $2.26^{\mathrm{b}}$ & $1.313^{\mathrm{b}}$ & $0.2^{\mathrm{b}}$ & $20.5^{b}$ & $0.203^{\mathrm{a}}$ \\
\hline & FL & Mean & $6.30^{\mathrm{b}}$ & $14.81^{\mathrm{c}}$ & $8.58^{c}$ & $1.74^{\mathrm{c}}$ & $47.67^{c}$ & $0.12^{\mathrm{a}}$ \\
\hline & & $\mathrm{P}$-value & 0.0041 & 0.004 & 0.0021 & $<.0001$ & $<.0001$ & 0.53 \\
\hline \multirow{4}{*}{$\stackrel{\Xi}{\Xi}$} & $\mathrm{CL}$ & Mean & $6.013^{\mathrm{a}}$ & $4.323^{\mathrm{a}}$ & $2.496^{\mathrm{a}}$ & $0.31^{\mathrm{a}}$ & $23.65^{\mathrm{a}}$ & $0.03^{\mathrm{a}}$ \\
\hline & UnL & Mean & $5.326^{\mathrm{b}}$ & $2.266^{\mathrm{b}}$ & $1.32^{\mathrm{b}}$ & $0.16^{\mathrm{b}}$ & $20.43^{b}$ & $0.19^{a}$ \\
\hline & FL & Mean & $6.2^{\mathrm{a}}$ & $14.81^{\mathrm{c}}$ & $8.57^{c}$ & $1.73^{c}$ & $47.67^{\mathrm{c}}$ & $0.12^{\mathrm{a}}$ \\
\hline & & $\mathrm{P}$-value & 0.0063 & 0.0041 & 0.002 & 0.002 & $<.0001$ & 0.53 \\
\hline \multirow{4}{*}{ 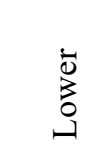 } & CL & Mean & $6.2^{\mathrm{a}}$ & $7.65^{\mathrm{a}}$ & $4.4^{\mathrm{a}}$ & $1.72^{\mathrm{a}}$ & $27.98^{\mathrm{a}}$ & $0.40^{\mathrm{a}}$ \\
\hline & UnL & Mean & $5.33^{b}$ & $2.23^{\mathrm{b}}$ & $1.30^{\mathrm{b}}$ & $0.17^{b}$ & $20.43^{b}$ & $0.42^{\mathrm{a}}$ \\
\hline & FL & Mean & $6.30^{\mathrm{a}}$ & $14.54^{\mathrm{c}}$ & $8.81^{\mathrm{c}}$ & $1.736^{\mathrm{c}}$ & $47.31^{\mathrm{c}}$ & $0.117^{\mathrm{a}}$ \\
\hline & & $\mathrm{P}$-value & 0.0042 & 0.0012 & $<.0001$ & $<.0001$ & $<.0001$ & 0.252 \\
\hline
\end{tabular}

Where, $\mathrm{CL}=$ conserved land, $\mathrm{UnL}=$ unconserved land, $\mathrm{FL}=$ forest land, $\mathrm{pH}=$ Power of hydrogen, $\mathrm{OM}=$ Organic matter, $\mathrm{OC}=$ Organic carbon, $\mathrm{TN}=$ Total nitrogen, $\mathrm{CEC}=\mathrm{Cation}$ exchange capacity and $\mathrm{EC}=$ Electrical conductivity. Means within column followed by the same letter are not statistically significant from each other at $\mathrm{P}>0.05$.

\section{Soil organic matter and organic carbon}

The difference in soil organic matter in all the three slope positions of the conserved, unconserved and the forest lands was statistically significant $(p<0.01)$. Highest mean value of soil organic matter $(14.81 \%)$ was recorded at the upper and middle slopes of the forest land. Comparing the two cultivated lands, higher soil organic matter (7.65\%) was recorded in the soil taken at the lower slope of the conserved land (Table 6). It could be due to deposition of different decomposable organic materials that were washed away by runoff from adjacent high slope areas and trapped by conservation structures at the lower slope. At the upper and middle slopes of the conserved area, soil organic matter (SOM) was found to be $5.84 \%$ and $4.32 \%$ respectively. However, lower values of SOM were recorded in all the three slopes levels of the unconserved farm land. As per the ratings of Birhanu (1980), the organic matter in the soils of the conserved land was high. But, it was medium in the soils of the unconserved land. This finding also agreed with the study conducted by Wolde et al. (2007) in Tigray region of Ethiopia. According to their finding, soil organic matter and soil nutrients in areas under conservation were different compared to the adjacent unconserved lands. The highest soil OM in the forest soils might be due to high amount of decomposed plant bodies. Similarly, Stroosnijder and Hoogmoed (2004) reported that rain water conserved through SWC structures is used for higher biomass production which in turn increases the organic matter content in the soil through litter and root decomposition.

Soil and water conservation measures contribute for both above and below ground biomass and hence improve soil organic carbon (SOC) by enhancing better ground cover. Similar to SOM, the difference in SOC in all the three slope positions of the conserved, unconserved and the forest lands were statistically significant $(\mathrm{p}<$ $0.01)$. The highest soil organic carbon $(8.58 \%)$ was considered at the lower slope of the forest land. The mean values of SOC in the upper slopes of the conserved and unconserved plots were $3.4 \%$ and $1.31 \%$ respectively. Comparing the two cultivated lands, higher mean value of SOC $(4.44 \%)$ was recorded in lower slope of the conserved land (Table 6). It might be attributed to the high concentration of SOM at the lower slope of the conserved land. Studies by Yihenew et al. (2009) and Kebede et al. (2011) reported that the unconserved fields have lower SOC as compared to fields with different conservation measures.

\section{Total nitrogen}

Statistically, significant difference $(\mathrm{p}<0.01)$ was observed in total nitrogen $(\mathrm{TN})$ of the soil samples taken from the upper and lower slopes of the conserved, unconserved and the forest lands. In the middle slope, the difference in total nitrogen between the conserved and unconserved lands was also significant $(p<0.01)$. The average value of TN was highest (1.74\%) in the soils of the natural forest and lowest $(0.16 \%)$ in the soils of the unconserved land. Next to the mean value of $\mathrm{TN}$ of the forest soil, relatively higher value of total nitrogen $(1.72 \%)$ was recorded in the lower slope of the conserved land. Considering the total nitrogen content in the different slope classes, mean value of TN recorded in the upper and middle slopes of the conserved land were $0.27 \%$ and $0.31 \%$ respectively (Table 6 ).

While, the recorded mean values of $\mathrm{TN}$ at the upper and lower slopes of the unconserved farm land were $0.2 \%$ and $0.17 \%$ respectively. The lower TN under unconserved farm land could be due to lower organic matter content. Similar study conducted by Mulugeta and Karl (2010) in southern Gondar revealed that higher total nitrogen was recorded in cultivated land with SWC measures than the unconserved land. Haweni (2015) also reported that total nitrogen in conserved lands of Dimma watershed was higher than the total nitrogen content in the corresponding sites without conservation measures. 


\section{Cation exchange capacity}

Cation exchange capacity (CEC) of the soil in the study area was significantly $(\mathrm{p}<0.01)$ affected by SWC practice. The highest mean value of CEC (47.67 $\left.\mathrm{Cmolckg}^{-1}\right)$ was recorded at the upper and middle slopes of the forest land. The cation exchange capacity recorded in upper, middle and lower slopes of the conserved land were $27.95 \mathrm{Cmolckg}^{-1}, 23.65 \mathrm{Cmolckg}^{-1}$ and $27.98 \mathrm{Cmolckg}^{-1}$ respectively. The lowest mean value of $\mathrm{CEC}$ $\left(20.43 \mathrm{Cmolckg}^{-1}\right)$ was observed under the middle and the lower slopes of the unconserved land. Zhang et al. (2007) reported that soil chemical properties found to be minimal at the top positions as compared to the lower positions of sloppy lands. Both clay and colloidal organic matter are negatively charged and therefore can act as anions. As a result, these two materials, either individually or combined as a clay-humus complex, have the ability to absorb and hold positively charged ions (cations). Soils with large amounts of clay and organic matter have higher CEC than sandy soils that are low in organic matter (Brady and Weil, 2002). As per the ratings of Hazelton and Murphy (2007), CEC in the soils of the conserved land was high. But, it was very high in the soils of the forest land.

\section{The status of available phosphorus and exchangeable bases}

Significant difference $(\mathrm{P}<0.01)$ in available phosphorus $(\mathrm{AP})$ was observed at the upper and lower slopes of the three lands. The mean value of AP in the conserved land was higher than the unconserved one in all slope levels. The higher mean value of AP recorded in the conserved land was 3.8ppm (Table 7). The finding revealed that mean value of AP was highest (5.9ppm) in upper and lower slopes of the forest land. Lower AP (2.43ppm) was recorded in the upper and middle slopes of the unconserved land. At the lower slope of the unconserved land, the average AP value was $2.45 \mathrm{ppm}$. The increase in amount of AP at the lower slope might be due to the downward movement of nutrients from the higher slope by runoff and accumulated at the lower slope. Previous investigations on soil properties along landscapes affected by long-term tillage indicated that soil AP content is lower in areas of soil removal than in areas of soil accumulation (Ashenafi et al., 2010). A study undertaken by Worku et al. (2012) in Goromti watershed of western Ethiopia showed that available phosphorous did not significantly vary with treatments and slope gradients.

Table 7: Status of AP and exchangeable bases in the cultivated and forest lands

\begin{tabular}{|c|c|c|c|c|c|c|c|}
\hline Slope & Treatment & & AP & $\mathrm{Ca}^{+2}$ & $\mathrm{Mg}^{+2}$ & $\mathrm{Na}^{+}$ & $\mathrm{K}^{+}$ \\
\hline \multirow{4}{*}{ 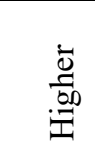 } & $\mathrm{CL}$ & Mean & $2.783^{\mathrm{a}}$ & $5.04^{\mathrm{a}}$ & $5.00^{\mathrm{a}}$ & $0.07^{\mathrm{a}}$ & $0.06^{\mathrm{a}}$ \\
\hline & UnL & Mean & $2.43^{\mathrm{a}}$ & $5.71^{\mathrm{b}}$ & $4.123^{b}$ & $0.146^{\mathrm{b}}$ & $0.12^{b}$ \\
\hline & FL & Mean & $5.90^{\mathrm{b}}$ & $18.56^{\mathrm{c}}$ & $5.04 \mathrm{a}$ & $0.15^{\mathrm{a}}$ & $1.08^{c}$ \\
\hline & & P-value & 0.007 & 0.002 & 0.002 & 0.041 & $<.0001$ \\
\hline \multirow{4}{*}{$\stackrel{\Xi}{\Xi}$} & $\mathrm{CL}$ & Mean & $3.116^{\mathrm{a}}$ & $7.50^{\mathrm{a}}$ & $2.506^{\mathrm{a}}$ & $0.23^{\mathrm{a}}$ & $0.13^{\mathrm{a}}$ \\
\hline & UnL & Mean & $2.43^{b}$ & $5.75^{b}$ & $4.13^{b}$ & $0.153^{b}$ & $0.12^{\mathrm{b}}$ \\
\hline & $\mathrm{FL}$ & Mean & $3.116^{\mathrm{a}}$ & $18.30^{\mathrm{a}}$ & $2.506^{\mathrm{a}}$ & $0.23^{\mathrm{a}}$ & $0.13^{\mathrm{a}}$ \\
\hline & & $\mathrm{P}$-value & $<.0001$ & 0.0033 & $<.0001$ & 0.034 & $<.0001$ \\
\hline \multirow{4}{*}{$\begin{array}{l}\dot{0} \\
\vdots \\
0 \\
\vdots\end{array}$} & $\mathrm{CL}$ & Mean & $3.80^{\mathrm{a}}$ & $7.80^{\mathrm{a}}$ & $6.10^{\mathrm{a}}$ & $0.10^{\mathrm{a}}$ & $0.13^{\mathrm{a}}$ \\
\hline & UnL & Mean & $2.45^{b}$ & $5.73^{b}$ & $4.13^{b}$ & $0.13^{\mathrm{a}}$ & $0.20^{\mathrm{b}}$ \\
\hline & $\mathrm{FL}$ & Mean & $5.901^{\mathrm{c}}$ & $18.92^{\mathrm{c}}$ & $5.043^{c}$ & $0.15^{b}$ & $1.07^{\mathrm{c}}$ \\
\hline & & $\mathrm{P}$-value & 0.006 & 0.0052 & $<.0001$ & 0.027 & $<.0001$ \\
\hline
\end{tabular}

Where, $\mathrm{CL}=$ conserved land, $\mathrm{UnL}=$ unconserved land, $\mathrm{FL}=$ forest land $\mathrm{AP}=$ available phosphorus, $\mathrm{Ca}, \mathrm{Na}, \mathrm{Mg}$ and $\mathrm{K}=$ exchangeable calcium, magnesium, sodium, and potassium respectively. Means within column followed by the same letter are not statistically significant from each other at $\mathrm{P}>0.05$.

The exchangeable bases $\left(\mathrm{Na}^{+}, \mathrm{K}^{+}, \mathrm{Mg}^{+2}\right.$ and $\left.\mathrm{Ca}^{+2}\right)$ are important properties of soil as they indicate the existing nutrient status. Exchangeable calcium $\left(\mathrm{Ca}^{+2}\right)$ was significantly $(\mathrm{P}<0.05)$ affected by SWC practice. In relation to conservation and slope, the highest $\left(7.80 \mathrm{Cmolckg}^{-1}\right)$ and lowest $\left(5.04 \mathrm{Cmolckg}^{-1}\right)$ mean value of exchangeable calcium were recorded at the lower and higher slopes of the conserved land respectively. But, the mean value of exchangeable calcium $\left(\mathrm{Ca}^{+2}\right)$ in the higher and lower slopes of the unconserved field were 5.71 $\mathrm{Cmolckg}^{-1}$ and $5.73 \mathrm{Cmolckg}^{-1}$ respectively. The recorded exchangeable calcium at the middle slope the unconserved plot was $5.75 \mathrm{Cmolckg}^{-1}$ (Table 7). Comparing the two cultivated lands with the natural forest, $\mathrm{Ca}^{+2}$ in the forest soil was highest. Mean values of $\mathrm{Ca}^{+2}$ in the higher, middle and lower slopes of the forest land were 18.56 $\mathrm{Cmolckg}^{-1}, 18.30 \mathrm{Cmolckg}^{-1}$ and $18.92 \mathrm{Cmolckg}^{-1}$ respectively. Similar report by Gebeyaw (2015) indicated that the status of exchangeable $\mathrm{Ca}^{+2}$ is lower in cultivated lands than in forest lands.

Considering the mean value of exchangeable magnesium $\left(\mathrm{Mg}^{+2}\right)$, the highest $\left(6.10 \mathrm{Cmolckg}^{-1}\right) \mathrm{was}_{\text {recorded }}$ in the lower slope of the conserved land and the lowest $\left(2.51 \mathrm{Cmolckg}^{-1}\right)$ was recorded at the middle slope of the conserved land. The recorded exchangeable magnesium in upper, middle and lower slopes of the forest land was 5.04 $\mathrm{Cmolckg}^{-1}, 2.5 \mathrm{Cmolckg}^{-1}$ and $5.43 \mathrm{Cmolckg}^{-1}$ respectively. In upper and middle slopes of the conserved land and the forest land, the difference in $\mathrm{Mg}^{+2}$ was not statistically significant (Table 7). It contradicts with the study undertaken by Gebeyaw (2015) in Maybar watershed of South Wollo Zone. His finding indicated that significant difference in exchangeable magnesium was observed between different land use types. According to his report, 
highest exchangeable magnesium content was recorded in the forest soil.

In the higher and middle slopes, significant difference $(\mathrm{p}<0.05)$ in exchangeable sodium $\left(\mathrm{Na}^{+}\right)$was observed between the conserved and unconserved farm lands. But, similar to the exchangeable magnesium, the difference in exchangeable sodium in both upper and middle slopes of the conserved land and the natural forest land was not significant (Table 7). In the lower slope, the difference in mean value of $\mathrm{Na}^{+}$between the conserved and unconserved lands was also insignificant. The highest mean value of exchangeable sodium $\left(0.23 \mathrm{Cmolckg}{ }^{-1}\right)$ was recorded in the middle slopes of conserved land and the natural forest land. In the higher slopes of conserved land and the natural forest, the recorded exchangeable sodium was $0.07 \mathrm{Cmolckg}^{-1}$ and 0.146 $\mathrm{Cmolckg}^{-1}$ respectively (Table 7$)$. The lowest mean value of $\mathrm{Na}^{+}\left(0.1 \mathrm{Cmolckg}^{-1}\right)$ was observed in the lower slope of the unconserved land. Similar study undertaken by Haweni (2015) in Dimma watershed revealed that exchangeable sodium was not significantly $(\mathrm{p}>0.05)$ affected by SWC practice and land slope.

Similarly, significant variation $(\mathrm{P}<0.01)$ in exchangeable potassium $\left(\mathrm{K}^{+}\right)$was observed between conserved and unconserved fields. But, the difference was not significant at the middle slopes of the conserved land and the natural forest land. The mean value of exchangeable potassium in the higher slope of the conserved land was $0.06 \mathrm{Cmolckg}^{-1}$. But, in middle and lower slopes of the conserved land it was found to be $0.13 \mathrm{Cmolc} / \mathrm{kg}$. In the unconserved land, $0.12 \mathrm{Cmolckg}^{-1}$ of exchangeable potassium was found in higher and middle slopes. $0.2 \mathrm{Cmolc} / \mathrm{kg}$ of exchangeable potassium was recorded at the lower slope of this land. The highest mean value of exchangeable potassium $\left(1.08 \mathrm{Cmolckg}^{-1}\right)$ was recorded at the upper slope of the forest land (Table 7). This might be due to very low erosion impact in the forest soil. Studies by Kyaruzi (2013) revealed that effective control of runoff improves exchangeable potassium. As per the ratings of FAO (2006), the exchangeable Ca and $\mathrm{Mg}$ were medium in the soils of the conserved and unconserved lands. But, the exchangeable $\mathrm{Na}$ in all the three lands was low whereas the exchangeable $\mathrm{K}$ content was very low in the soils of the conserved and unconserved lands.

\section{CONCLUSION}

Land degradation is causing a decline in crop productivity and huge economic loss, putting the food security and livelihood of farmers at risk. Most of the soil physicochemical properties were significantly affected by SWC measures. Soil bulk density was highest in unconserved land but lowest in the soil of the natural forest. Relatively, high mean value of sand was recorded in soils of the natural forest. Comparing the two agricultural lands, higher mean value of soil moisture and clay content were recorded in soils of the conserved land. The soil chemical properties including SOM, SOC, TN, AP and the exchangeable bases in soil of the conserved farm land were higher compared to the conserved one. Therefore, this study clearly indicated that, SWC practice is essential measure to solve the wide spread soil nutrient loss due to soil erosion in the district.

\section{REFFERENCES}

Abay Challa, Abdu Abdelkadir \& Tefera Mengistu (2016). Effects of graded stone bunds on selected soil properties in the central highlands of Ethiopia. International Journal of Natural Resource Ecology and Management, 1(2), 42-50.

Ashenafi Ali, Abayneh Esayas \& Sheleme Beyene (2010). Characterizing soils of Delbo Wegene watershed, Wolaita Zone, southern Ethiopia for planning appropriate land management. Journal of Soil Science and Environmental Management, 1(8), 184-199.

Baruah, T. C., \& Barthakur, H. P. (1997). A textbook of soils analysis. Vikas Publishing House Private Limited, New Delhi: India, pp. 256.

Bello, O. B., Abdulmaliq, M., \& Afolabis, A. (2010). Correlation and path coefficient analysis of yield and agronomic characters. African Journal of Biotechnology, 9(18), 2633-2639.

Berhanu Debele (1980). The physical criteria and their rating proposed for land evaluation in the highland region of Ethiopia. Land Use Planning and Regulatory Department, Ministry of Agriculture, Addis Ababa, Ethiopia.

Bremner, J. M., \& Mulvaney, C. S. (1982). Methods of soil analysis. American Society of Agronomy. p. 595624.

Cottenie, A. (1980). Soil and plant testing as a basis of fertilizer recommendations. Food and Agriculture Organization of the United Nations, Rome, Italy.

Coxhead, I., \& Ygard, R. (2008). Land degradation. Submitted for Copenhagen consensus comments. University of Wisconsin-Madison and Norwegian University of Life Sciences.

Environmental Protection Authority (EPA). (2003). State of Environment Report for Ethiopia. Addis Ababa, Ethiopia.

Food and Agriculture Organization (FAO). (2006). Plant nutrition for food security: A guide for integrated nutrient management. Fertilizer and Plant Nutrition, Rome, Italy.

Gebeyaw Tilahun (2015). Assessment of soil fertility variation in different land uses and management practices 
in Maybar watershed, South Wollo Zone, Northern Ethiopia. International Journal of Environmental Bioremediation and Biodegradation, 3(1), 15-22.

Gee, G. W., \& Bauder, J. W. (1986). Particle size analysis. American Society of Agronomy, 7, 383-411.

Habtamu Kassahun, Husien Oumer, Haimanote Bayabil \& Tegenu Engda (2009). The effect of land use on plant nutrient availability and carbon sequestration. pp. 208-219. Proc. of the $10^{\text {th }}$ conference on "Natural Resources Management" March 25-27. Ethiopian Society of Soil Science, Addis Ababa.

Haweni Habtamu (2015). Effect of soil and water conservation on selected soil characteristics in Dimma watershed, central Ethiopia. MSc thesis. Addis Ababa University, Addis Ababa, Ethiopia.

Hazelton, P., \& Murphy, B. (2007). Interpreting soil test results: What do all the numbers mean? (2nd ed.). CSIRO Publishing. p. 152.

Joas, T. (2015). Effects of soil and water conservation techniques on soil productivity and bean grain yield in Nyamasheke District, Rwanda. MSc thesis. Kenyatta University, Kenya.

Kebede Wolka, Awdenegest Moges \& Fantaw Yimer (2011). Effects of level soil bunds and stone bunds on soil properties and its implications for crop production: the case of Bokole watershed, Dawuro zone, Southern Ethiopia. Agricultural Science, 2(3), 357-363.

Kessler, C. A. (2006). Decisive key factors influencing farmers' soil and water conservation investments. Wageningen University, Netherland.

Kyaruzi, L. (2013). Relationship between soil and landform derived land qualities and conservation agriculture practices in West Usambara Mountains, Tanzania. MSc thesis. Sokoine University of Agriculture, Tanzania. pp 140 .

Lemma Tiki, Menfes Tadesse \& Fantaw Yimer (2015). Effects of integrating different soil and water conservation measures into hillside area closure on selected soil properties in Hawassa Zuria District, Ethiopia. Journal of Soil Science and Environmental Management, 6(10), 268-274.

Moberg, J. R. (2000). Soil and plant analysis manual. The Royal Veterinary and Agricultural University, Copenhagen, Denmark. 133 pp.

Mojiri, A., Aziz, H. A., \& Ramaji, A. (2012). Potential decline in soil quality attributes as a result of land use change in a hillslope in Lordegan, Western Iran. African Journal of Agricultural Research, 7(4), 577-582.

Motsara, M., \& Roy, R. (2008). Guide to laboratory establishment for plant. FAO Fertilizer and Plant Nutrition Bulletin 19, Rome. 219pp.

Mulugeta Demelash \& Karl Stahr (2010). Assessment of integrated soil and water conservation measures on key soil properties in Southern Gondar, North-Western High lands of Ethiopia. Agriculture, Ecosystem and Environment, 105, 373-386.

Olsen, S. R., Cole, C. V., Wanatabe, F. S., \& Dean, L. A. (1954). Estimation of available phosphorus in soils by extraction with sodium bicarbonate. USDA Circular, p. 939.

Papiernik, S. K., Lindstrom, M. J., Schumacher, T. E., Schumacher, J. A., Malo, D. D., \& Lobb, D. A. (2007). Characterization of soil profiles in a landscape affected by long-term tillage, Soil and Tillage Research, 93, 335-345.

Pimentel, D., \& Burgess, M. (2013). Soil erosion threatens food production. Cornell University, USA.

Rhoades, J. D., Miller, R. H., \& Keeney, D. R. (1982). Methods of soil analysis. American Society of Agronomy. p. 39-79.

Schnitzer, M. (1982). Methods of Soil Analysis. Agronomy Monograph. American Society of Agronomy. Pp. 539577.

Singh, B., \& Tripathi, A. (2013). Environmental science, Indian publisher ( $1^{\text {st }}$ ed.).

Statistical Analysis System (SAS). (2008). Institute Inc. SAS/STAT 9.2 user's guide. SAS Institute, USA.

Stroosnijder, L., \& Hoogmoed, W. (2004). The contribution of soil and water conservation to carbon sequestration in semi-arid Africa. Bull. Res. Erosion, 23, 528-539.

Teshome Yitbarek, Heluf Gebrekidan, Kibebew Kibret \& Shelem Beyene (2013). Impacts of land use on selected physicochemical properties of soils of Abobo area, western Ethiopia. Agriculture, Forestry and Fisheries, 2(5), 177-183.

Wasim, I., Chattopadhayay, K., Majumdar, G., \& Sulewski, D. (2010). Use of village-level soil fertility maps as a fertilizer decision support tool in the red and lateritic soil zone of India. Better Crops, 94(3).

Woldeamlak Bewket (2001). The need for participatory approach to soil and water conservation in the Ethiopian highlands: A case study in Chamoga watershed, East Gojjam, Ethiopia.

Wolde Mekuriya, Veldkamp, E., Mitiku Haile, Nyssen, J., Muys, B., \& Kindeya, G. (2007). Effectiveness of exclosures to restore degraded soils as a result of overgrazing in Tigray, Ethiopia. Journal of Arid Environment, 69(2), 270-284.

Worku Hailu, Awdenegest Moges \& Fantaw Yimer (2012). The effects of 'fanyajuu' soil conservation structure on selected soil physical and chemical properties: the case of Goromti watershed, Western Ethiopia. 2(4), 132-140. 
Yihenew Gebreselassie, Tadele A., Mitiku Haile \& Yamoah, C. (2009). Lessons from upstream soil conservation measures to mitigate soil erosion and its impact on upstream and downstream users of the Nile River. International Water Management Institute. pp. 170-183.

Zhang, Q., Fua, B., Chen, L., Zhaoa, W., \& Gulinck, H. (2007). Dynamics and driving factors of agricultural landscape in the semiarid hilly area of the Loess Plateau, China. Agriculture, Ecosystems and Environment, $103(3), 535-543$. 